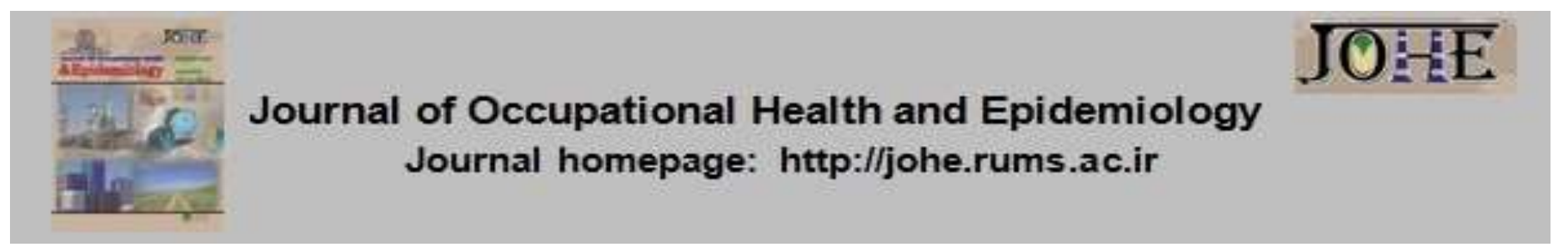

\title{
Correlation between occupational burnout and personality dimensions among physicians working in hospitals of Rafsanjan University of Medical Sciences, Iran, 2016
}

Mohammadreza Mirzabeigi ${ }^{1}$, Parvin Agha Mohammad Hasani ${ }^{1}$, Mahmood Sheikh-Fathollahi² Mohammadreza Mokhtare $\mathrm{e}^{3^{*}}$

1- Assistant Prof., Department of Psychiatry, Rafsanjan University of Medical Sciences, Rafsanjan, Iran.

2- Assistant Prof., Occupational Environment Research Center, Medical School, Rafsanjan University of Medical Sciences, Rafsanjan, Iran.

3- MSc of Educational Psychology, Social Determinants of Health Research Center, Rafsanjan University of Medical Sciences, Rafsanjan, Iran.

Citation: Mirzabeigi M, Agha Mohammad Hasani P, Sheikh-Fathollahi M, Mokhtaree M.
Correlation between occupational burnout and personality dimensions among physicians
working in hospitals of Rafsanjan University of Medical Sciences, Iran, 2016. JOHE. 2018;
$7(3): 153-9$.

Article Info

* Corresponding authors:

Mohammadreza Mokhtaree,

E-mail:

mrmokhtaree@yahoo.com

\section{Article history}

Received: Feb, 2018

Accepted: Jul, 2018

10.29252/johe.7.3.153

Print ISSN: 2251-8096 Online ISSN: 2252-0902

Peer review under responsibility of Journal of Occupational Health and Epidemiology

\begin{abstract}
Background: Occupational burnout is an emotional response to chronic occupational stress. The aim of this study was determine the rate of occupational burnout among physicians working in Rafsanjan University hospitals Rafsanjan, Iran, and its correlation with personality dimensions: 2016 .

Materials and Methods: In this descriptive and correlational study, 161 physicians were recruited using the census method. After obtaining informed consent, respondents filled in the Revised NEO Personality Inventory (NEO PI-R) and Maslach Burnout Inventory. Data were analyzed using independent t-test, one-way analysis of variance (ANOVA), and multiple linear regression.

Results: Gender, age, and working experience did not have a significant association with occupational burnout ( $P>0.050)$. Moreover, $16(9.9 \%), 139(86.3 \%)$, and $6(3.7 \%)$ of the physicians had low, moderate, and high occupational burnout, respectively. The mean score of emotional fatigue of women $(P=0.015)$ and individuals aged $35-50$ years $(P=$ 0.400 ) was higher. The association of job burnout was significant and inverse with all dimensions of personality and significant with the personality dimension of neuroticism ( $P$ $<0.001)$. Regression analysis indicated that $23.8 \%$ of occupational burnout was predictable by the personality dimension of extroversion $[P=0.021]$.

Conclusions: Ninety percent of the physicians had moderate to severe occupational burnout that was related to some personality dimensions. Since doctors play an important role in promoting community health, it seems necessary that trustee organizations, while investigating the factors affecting occupational burnout and trying to improve the status quo, use personality assessment as part of the appointment and organization process.
\end{abstract}

Keywords: Occupational Burnout, Personality, Physician, Iran

\section{Introduction}

Motility and mobility are necessary for human life and mental stresses are useful for human mobility and effort; however, high rates of disturbing tensions diminish the efficiency of human resources, and hence, reduce the efficiency of the organization and weaken its foundations (1). Occupation is one of the most important sources of mental stress and the phenomenon of occupational burnout is one of the main occupational issues usually seen as a response to occupational and organizational tensions among employees of different organizations (2).

Occupational burnout is a consequence of permanent and frequent occupational pressures. As a consequence, the individual feels stressful in his working environment due to internal and external factors, which, in case of continuation, eventually changes into a sense of burnout (3). The consequences of this phenomenon include individual issues like the incidence of some 
psychological disorders such as anxiety and depression (4), loss of organizational happiness (5), reduction of organizational commitment and job satisfaction, tendency to quit, and occupational stagnation (6), reduction of employee participation (7), organizational silence (8), deviant behavior (9), reduction of occupational creativity (10), and distance of the organization from its objectives and reduction of productivity (11).

Maslach considered occupational burnout as a psychological symptom that was a combination of emotional burnout, depersonalization, and lack of individual success (12). This multifactor phenomenon is influenced by various individual and environmental factors. Saatchi considered individual factors as the most important and most specific cause of occupational burnout, as he believed that the individuals themselves cause their own burnout because of ineffective performance (13). Personality is the most important individual factor which plays an important role in the occupational performance of individuals, because it specifies their motivation and attitude towards the job and the way in which the individuals respond to job requirements $(14,15)$. According to Cervone and Pervin, personality is a pattern of thinking, feeling, and behavior based on individual characteristics in conjunction with the hidden or apparent psychological mechanisms behind these patterns (16); therefore, the personality of each individual can explain the level of his/her occupational burnout. The high amount of workload resulting from the type of occupation gradually diminishes individuals' physical and mental capabilities and job satisfaction and may discourage them from engaging in their profession. All of these factors may result in occupational burnout. Some of these stresses are inevitable and professional requirements $(17,18)$.

The results of previous studies indicate that occupations which impact the health of individuals are considered as stressful occupations. This stress is higher among doctors due to sensitivity in decision making, long working hours, and judicial complaints (19). In health care organizations, occupational burnout is important because of the direct relationship with community health. Since such a study has not been conducted in the community of physicians working in Rafsanjan University of Medical Sciences, Rafsanjan, Iran, until today, and an estimate of occupational burnout is not available in this society in Rafsanjan, this study was performed with the aim to assess occupational burnout among physicians occupied in Rafsanjan University of Medical Sciences in 2016 and its association with personality dimensions.

\section{Materials and Methods}

The statistical population of this descriptivecorrelational study included all doctors (specialist, and general doctors) employed in hospitals affiliated to Rafsanjan University of Medical Sciences in 2016 $(n=161)$ all of whom were included in the study (100\% response rate).

The study inclusion criteria were employment at the time of conducting the study and work experience of more than 6 months. In addition, the exclusion criteria included a history of mental illness leading to hospitalization or drug treatment, a history of death of close relatives during the past 3 months, divorce during the past year, severe marital conflicts requiring psychological counseling, reluctance to participate in the study, and incomplete questionnaire.

The demographic characteristics checklist including questions on age, gender, and working experience, and the Revised NEO Personality Inventory (NEO $\mathrm{PI}-\mathrm{R}$ ), and Maslach Burnout Inventory (MBI) were exploited to collect data. In the first step, the license of the study was obtained, then, the names of all physicians were obtained from the staff department offices of the Ali-ibn Abi Talib, Moradi, and Nikanfs hospitals. In the next step, the researchers referred to the work place of the doctors and explained the purpose of the study to them. If the participants provided an informed consent, their emails were received. Using the Google Docs software, the questionnaires were designed electronically and the link of the loading site of the questionnaire was sent to the participants. After answering the questions, the participants returned the questionnaires to the sender (the plan executor). In this method, only the responses were displayed for the researcher and the sender remained unknown. Thus, the principle of confidentiality was observed in the research and the participants were also aware of this issue.

The NEO PI-R was prepared by McCrae and Costa with 181 items in 1985. After several revisions, its current version (NEO-PI-R) with 60 items is used (20). In Iran, Garrosi et al. translated this questionnaire into Persian, and then, investigated its functional structure. The 60 items of this questionnaire were scored based on a 5-point Likert scale ranging from 4 to 0 (completely agree, agree, no comment, disagree, and completely disagree, respectively). Each 12 items of the questionnaire examined one of the five major factors of personality (neuroticism, extroversion, flexibility, pleasure, and responsiveness). The range of score for each scale was $0-48$. This questionnaire lacked a total score. A high score in any personality trait indicated the high intensity of that trait. NEO PI-R scales were of high validity and correlation between scales was high 
(21). In a study by Mirzaie et al., the Cronbach's alpha coefficient of the factors of this questionnaire ranged from 0.680 to 0.881 ; moreover, the total Cronbach's alpha and the retest validity of the total score were 0.95 and 0.633 , respectively (22). In the present study, Cronbach's alpha of the questionnaire dimensions and the whole questionnaire was obtained in the range of 0.660 to 0.875 and as 0.910 , respectively.

The MBI consisted of 22 items with the 3 aspects of occupational burnout (emotional exhaustion, depersonalization, and feeling of personal accomplishment). The items were scored based on a 7-point Likert scale ranging from 0 to 6 with the options of never, rarely, on few instances, sometimes, frequently, often, and always, respectively. In the MBI, 9, 5, and 8 items are related to emotional exhaustion, depersonalization, and feeling of personal accomplishment (personal success), respectively. Regarding the emotional exhaustion subscale, a score of above 30 , between 18 to 29 , and less than 17 indicated, respectively, high, moderate, and low emotional exhaustion. In the subscale of depersonalization, a score of higher than 12, between 6 to 11 , and less than 6 represented high, moderate, and low depersonalization, respectively. Regarding the subscale of individual performance, a score above 40, 34-39, and less than 33 illustrated high, moderate, and low individual performance, respectively. The high score of emotional exhaustion and depersonalization and the low score of individual success reflected occupational burnout. Maslach and Jackson have reported an internal reliability coefficient of $0.90,0.79$, and 0.71 , respectively, for emotional exhaustion, depersonalization, and individual success (23). The scientific validity of this questionnaire was first confirmed by Filian in Iran and its reliability coefficient was reported to be 0.78 (24).

Finally, the data were analyzed using statistical tests in the SPSS software (version 17.0, SPSS Inc., Chicago, IL, USA). Skewness and elongation of occupational burnout scores and the significance level of the Kolmogorov-Smirnov test of this variable were in the range of \pm 2 and less than 0.050 , respectively. However, according to the central limit theorem (CLT) and the high sample size $(25,26)$, the chi-square test, Pearson correlation, one-way analysis of variance (ANOVA), independent t-test, and multiple linear regression were used for data analysis. In addition, the significance level of the tests was considered to be 0.050 .

\section{Results}

Of the 161 physicians under study, 70 (43.5\%) and $91(56.5 \%)$ were men and women, respectively, and $105(65.2 \%)$ individuals had a working experience of less than 15 years. Moreover, 41 (25.5\%), 83 $(51.6 \%)$, and $37(23.0 \%)$ of the physicians were, respectively, under $35,35-50$, and over 50 years of age. Of these subjects, 60 individuals (94.90\%) and the remaining 145 (90.06\%) were general practitioners and specialists, respectively. Moreover, $16(9.9 \%), 139(86.3 \%)$, and $6(35.7 \%)$ of the doctors had low, moderate, and severe occupational burnout, respectively.

The mean and standard deviation (SD) of the occupational burnout score was $49.47 \pm 10.99$ with the highest mean related to emotional exhaustion $(24.68 \pm 5.08)$. The significance level of the homogeneity of variance (HOV) test was 0.803 . The results of the independent t-test and one-way ANOVA showed that there was no significant difference between the mean scores of occupational burnout in terms of gender $(P=0.109)$, service record $(P=0.277)$, and age $(P=0.339)$. Dimensions of occupational burnout were also examined. Mean score of emotional exhaustion was higher among women $(P=0.015)$ and the age group of 35-50 years $(P=0.040)$. The dimensions of occupational burnout were not significantly correlated with the service record $(P>0.050)$ (Table 1).

Table 1: Mean and standard deviation of occupational burnout and its dimensions among physicians working in hospitals of Rafsanjan University of Medical Sciences, Rafsanjan, Iran, by some demographic characteristics in 2016

\begin{tabular}{|c|c|c|c|c|c|}
\hline Variable & & Job burnout & Depersonalization & $\begin{array}{l}\text { Emotional } \\
\text { exhaustion }\end{array}$ & $\begin{array}{c}\text { Personal } \\
\text { accomplishment }\end{array}$ \\
\hline \multirow{3}{*}{ Gender } & Men & $47.94 \pm 10.93$ & $7.59 \pm 3.93$ & $23.59 \pm 5.68$ & $16.77 \pm 7.88$ \\
\hline & Women & $50.74 \pm 10.93$ & $7.14 \pm 2.98$ & $25.58 \pm 4.36$ & $18.02 \pm 9.58$ \\
\hline & ${ }^{\star *} \mathbf{P}$ & 0.109 & 0.408 & 0.015 & 0.036 \\
\hline \multirow{3}{*}{ Work experience (year) } & $\leq 15$ & $50.16 \pm 9.54$ & $7.55 \pm 3.35$ & $25.22 \pm 4.60$ & $17.39 \pm 8.55$ \\
\hline & $>15$ & $48.18 \pm 13.28$ & $6.95 \pm 3.59$ & $23.66 \pm 5.80$ & $17.57 \pm 9.45$ \\
\hline & ${ }^{* *} \mathbf{P}$ & 0.277 & 0.289 & 0.085 & 0.902 \\
\hline \multirow{4}{*}{ Age (year) } & $<35$ & $49.29 \pm 10.13$ & $7.85 \pm 3.26$ & $24.02 \pm 5.48$ & $17.41 \pm 8.14$ \\
\hline & $35-50$ & $50.52 \pm 1063$ & $7.11 \pm 3.27$ & & $17.78 \pm 9.44$ \\
\hline & $>50$ & $47.32 \pm 12.56$ & $7.30 \pm 3.40$ & $23.27 \pm 6.21$ & $16.76 \pm 8.67$ \\
\hline & $\star \star \star \star \mathbf{P}$ & 0.339 & 0.526 & 0.040 & 0.843 \\
\hline
\end{tabular}


The results of Pearson correlation test indicated that occupational burnout had a significant and inverse relationship with the personality dimensions of conscientiousness, extroversion, agreeableness, and Openness to experience and a significant and direct relationship with the personality dimension of neuroticism $(P<0.001)$ (Table 2$)$.

Table 2: Correlation coefficients of personality dimensions with occupational burnout and its dimensions among physicians working in hospitals of Rafsanjan University of Medical Sciences, Rafsanjan, Iran, in 2016

\begin{tabular}{lcccc}
\hline \multirow{2}{*}{$\begin{array}{c}\text { Personality } \\
\text { dimensions }\end{array}$} & \multicolumn{4}{c}{ Occupational burnout and its dimensions } \\
\cline { 2 - 5 } Conscientiousness & $\mathrm{r}=-0.351$ & $\mathrm{r}=-0.256$ & $\mathrm{r}=-0.287$ & $\mathrm{P}=-0.172$ \\
& $\mathrm{P}<0.001$ & $\mathrm{P}=0.001$ & $\mathrm{P}<0.001$ & $\mathrm{P}=0.029$ \\
\hline \multirow{2}{*}{ Extraversion } & $\mathrm{r}=-0.464$ & $\mathrm{r}=-0.198$ & $\mathrm{r}=-0.511$ & $\mathrm{P}=-0.205$ \\
& $\mathrm{P}<0.001$ & $\mathrm{P}<0.001$ & $\mathrm{P}<0.001$ & $\mathrm{P}=0.009$ \\
\hline \multirow{2}{*}{ Agreeableness } & $\mathrm{r}=-0.459$ & $\mathrm{r}=-0.144$ & $\mathrm{r}=-0.570$ & $\mathrm{P}=-0.186$ \\
& $\mathrm{P}<0.001$ & $\mathrm{P}=0.068$ & $\mathrm{P}<0.001$ & $\mathrm{P}=0.018$ \\
\hline Openness to & $\mathrm{r}=-0.324$ & $\mathrm{r}=-0.052$ & $\mathrm{r}=-0.454$ & $\mathrm{r}=-0.122$ \\
experience & $\mathrm{P}<0.001$ & $\mathrm{P}=0.510$ & $\mathrm{P}<0.001$ & $\mathrm{P}=0.125$ \\
\hline \multirow{2}{*}{ Neuroticism } & $\mathrm{r}=-0.462$ & $\mathrm{r}=0.053$ & $\mathrm{r}=0.667$ & $\mathrm{r}=0.169$ \\
& $\mathrm{P}<0.001$ & $\mathrm{P}=0.502$ & $\mathrm{P}<0.001$ & $\mathrm{P}=0.032$ \\
\hline
\end{tabular}

Multiple linear regression was used to predict occupational burnout among doctors based on personality dimensions, age, gender, and work experience. The Durbin-Watson statistic was equal to 1.591 and the assumption of collinearity of the variables was rejected (VIF $=1.034-45.183$, tolerance $<0.022$ ). Figures 1 and 2 demonstrate the frequency distribution of error and the dispersion of the occupational burnout variable, respectively. The regression equation was significant given the CLT and the sample size $(P<0.001)$. Moreover, $23.8 \%$ of occupational burnout was explained based on personality dimensions, age, gender, and work experience. Furthermore, the personality dimension of extroversion was able to predict occupational burnout among the physicians $(P=0.021, t=-$ 2.337) (Table 3).

Table 3: Prediction of occupational burnout among physicians working in hospitals of Rafsanjan University of Medical Sciences, Rafsanjan, Iran, in 2016 based on dimensions of personality, age, gender, and work experience

\begin{tabular}{|c|c|c|c|c|c|}
\hline \multirow{2}{*}{ Model (Inter) } & \multicolumn{2}{|c|}{ Non-standardized coefficients } & \multirow{2}{*}{$\frac{\text { Standardized coefficients }}{\beta}$} & \multirow{2}{*}{$\mathbf{t}$} & \multirow{2}{*}{$\mathbf{P}$} \\
\hline & $\mathbf{B}$ & Standard error & & & \\
\hline Fixed & 57.20 & 6.51 & & 8.79 & $<0.001$ \\
\hline Conscientiousness & 3.70 & 2.63 & 0.494 & 1.41 & 0.161 \\
\hline Extraversion & -8.76 & 3.76 & -1.09 & -2.33 & 0.021 \\
\hline $\begin{array}{l}\text { Openness to } \\
\text { experience }\end{array}$ & 1.34 & 1.29 & 0.169 & 1.04 & 0.300 \\
\hline Neuroticism & 0.29 & 1.84 & 0.041 & 0.16 & 0.875 \\
\hline Age & -0.098 & 1.58 & -0.006 & -0.062 & 0.951 \\
\hline Sex & 1.46 & 1.57 & 0.066 & 0.93 & 0.352 \\
\hline Work experience & 0.237 & 2.32 & 0.010 & 0.102 & 0.919 \\
\hline
\end{tabular}

\section{Discussion}

Nearly $90 \%$ of physicians of Rafsanjan University of Medical Sciences who participated in the study had moderate and severe occupational burnout. This level of exhaustion among the community of doctors confirms the results of a number of national and international studies (27-29).

This issue is a danger to healthcare practitioners, so effective steps should be taken to reduce the burden by further reviewing and taking into account personal and environmental factors associated with the problem. The medical profession and its various branches, as one of the most stressful occupations, can affect the mental health of doctors, and in turn that of patients. Moreover, among the various specialties, there are specialties that face more work pressure, and are more exposed to unwell and elderly, chronic, and incurable patients as well as a state of urgency in their careers, which contribute to the creation of psychological tension, and consequently, have a determinant role in occupational burnout (30).

In the present study, the relationship between occupational burnout and personality disorder was significant, which is consistent with the results of research studies by Muharramzadeh et al. (31), Esfahani Savabi et al. (32), and Magnano (33). The four personality dimensions of extroversion, Openness to experience, agreeableness and 
conscientiousness, which have an inverse relationship with exhaustion, are open-ended personality dimensions that represent people with the characteristics of excitable, passionate, trustworthy, friendly, conscientious, self-reliant, and cautious in making decisions. These personality traits make people more tolerant of various occupational and environmental stresses, and thus, render a person more resistant to occupational burnout (34).

The relationship between personality depersonalization and the personality dimensions of conscientiousness and extroversion was significant and inverse. Conscientiousness indicates the credibility of the individual, and depersonalization is pessimistic tendencies and negative responses to those who are usually considered to be recipients of services offered by the individual (35). Depersonalization occurs when a person makes an arid response, and shows lack of interest in human relationships and overindulgence in the implementation of laws and regulations, or carries out work only through the implementation of administrative regulations, which is the same as the lack of human relationships which render the individual soulless (12). Conscientious and extroverted employees utilize the effort, perseverance, and positive motivation that have provided them with the conditions for their personality to be well-trusted, and thus, decline their levels of depersonalization, which is largely in accordance with the results of the researches of Sharma and Kashyap (36), Zimmerman et al. (37), and Azeem (38).

The relationship between emotional exhaustion and personality disorder was significant. This finding is consistent with the results of a number of researches (2, 39-42). Among all aspects of occupational burnout, emotional exhaustion is the most significant and most obvious exhaustion (43). Emotional exhaustion appears with symptoms such as chronic fatigue, sleep problems, and some physical symptoms in humans (44). Every time such people refer to occupational burnout, in fact, they are referring to their experience of emotional exhaustion. According to Maslach, the positive aspect of emotional exhaustion is equivalent to the term energy. It means that getting a higher score in emotional exhaustion is a sign of energy reduction (12). These people are more susceptible to stress and pressure (45); therefore, it is understandable that people with more emotional exhaustion feel higher levels of anxiety, hostility, depression, acceleration, and vulnerability, which represent neuroticism. The results of this study confirm this issue.
According to another finding of this study, there was a reduction in the individual success rate of physicians with neuroticism, which was consistent with the study of Swider and Ghorpade $(37,41)$. Individual success is a condition in which individuals have positive perceptions in their professional efforts and feel that they are progressing in their own jobs and that their work, career, and efforts have positive outcomes. The response of individuals with neuroticism to stressors is poor, so there is a high probability of them treating an ordinary situation as a threat and interpreting small failures as a great frustration. Therefore, they have no positive belief in professional progress and consider success to be unattainable (46).

In this study, given the fact that the subject had to comment on organizational factors, despite the assurance of anonymity in the questionnaires, some refused to respond to the questionnaire due to concerns about the consequences. Moreover, doctors who were aware of the probable outcome of the questionnaire, given their level of education, gave answers that led to their desired results. Common variance error was one of the other constraints. When prediction and criterion variables are derived from the same source, the relationship between the variables may be due to a self-report error. In this study, factors such as expertise, income, marital status, and occupational stress that could have had an impact on occupational depression were not investigated. In future studies, it is suggested that, in addition to personality factors, the abovementioned factors be considered as moderating variables. This research was carried out in Rafsanjan University of Medical Sciences; thus, it is recommended that other organizations be considered in order to increase the generalizability of the results and provide the possibility to compare the results of this study with other studies.

\section{Conclusion}

Based on the findings of this study, $90 \%$ of physicians had some degree of occupational burnout associated with different personality dimensions. Since physicians play a significant role in promoting the health of the community, it seems necessary that trustee organizations, while investigating the factors affecting occupational burnout and trying to improve the status quo, exploit the personality assessment based on the five-factor model as part of the appointment and organization process.

\section{Acknowledgement}

The researchers would like to thank all the doctors who, in spite of their work burden, broad-mindedly 
collaborated with the executives of this study. In addition, the material and spiritual support of the research deputy of Rafsanjan University of Medical Sciences is appreciated.

\section{Conflict of interest: None declared.}

\section{References}

1. Goudarzi $M$, Keshtidar M. The correlation between personal characteristics and burn-out among managers in faculties of physical and non physical education universities. Harkat 2002; 13(13):45-53.

2. Naseh $M$, Jalilvand $J$, Vahdani $M$. Relationship between personality dimensions and job burnout of nurses. Modern Care Journal 2012; 9(2):87-94.

3. Staten A, Lawson E. GP wellbeing: combatting burnout in general practice. 1st ed. Boca Raton, Florida, United States: CRC Press; 2017

4. Yavari M, Shamsaie F, Yazdanbakhsh K. Comparison psychiatrics nurses' burnout and general health with critical care (ICU) nurses. Quarterly Journal of Nersing Management 2014; 3(1):55-65.

5. Shabani Bahar Gh, Shokri M, Khodabandeh Loo V. Determining the relationship between organizational happiness and job burnout in the staff of sport and youth offices of Hamedan province. New Trends in Sport Management 2016; 4(14):95-105.

6. Beheshtifar M, Amiresmaili MR, Khosravi S, Mirzaei S, Oroomiei N. The relationship between career plateau and job burnout among employees of teaching hospitals affiliated to Kerman University of Medical Sciences, 2012. Journal of Health and Development 2016; 5(2):166-74.

7. Ghasemi Roshnavand J, Khoshbakhti J. The relationship of employees' participation, resistance to change and staff burnout in youth and sport administration of great khorasan. Applied Research of Sport Management 2014;3(1):73-84.

8. Sharifi A. Determine of relationship between organizational silence and jop burnout staffs of department of sport and youth Hamedan province. Contemporary Studies on Sport Management 2016; 6(11):51-61.

9. Khorasani $\mathrm{H}$. The relationship between burnout and deviant behavior case study: Sport and Youth Organization of Northern Khorasan. Applied Reserarch of Sport Management 2016; 4(3):79-90.

10. Noroozi AR, Amirianzadeh M. The relationship between job motivation and creativity with the professional performance of Jahrom teachers. Journal of Educational Administration Research Quartery 2016; 7(28):31-50.

11. Rasoli Z. Survey relationship job stress and burnout with rat productivity in helicopter pilots. Annals of Military and Health Sciences Research 2012; 10(2):133-7.

12. Maslach C, Schaufeli WB, Leiter MP. Job burnout. Annu Rev Psychol 2001; (52):397-422.

13. Saatchi M. Productivity psychology. 2nd ed. Tehran: Virayesh; 2003.

14. Furnham A, Eracleous A, Chamorro-Premuzic $T$. Personality, motivation and job satisfaction: Hertzberg meets the Big Five. Journal of Managerial Psychology 2009; 24(7-8):765-79.

15. Azizi Y, Noordin Y, Abdul Talib B, Sharifuddin I, Norzana MN. The relationship between big five personality with work motivation, competitiveness and job satisfaction. Psychology 2012; (44):7454-61.

16. Cervone D, Pervin LA. Personality, theory and research. 11th ed. Hoboken, New Jersey, United States: John Wiley \& Sons, Inc; 2009.

17. Ghanei Gheshlagh R, Valiei S, Rezaei M, Rezaei K. The relationship between personality characteristics and nursing occupational stress. Iranian Journal of Psychiatric Nursing 2013; 1(3):27-34.

18. Nesayan A, Assadi Gandomani R, Bagheri $H$. Relationship between job stress and nurses' personality traits and spiritual experiences. Iranian Journal of Nursing Research 2017; 12(3):44-9.

19. Wong ML, Anderson J, Knorr T, Joseph JW, Sanchez LD. Grit, anxiety, and stress in emergency physicians. Am J Emerg Med 2018; 36(6):1036-9.

20. McCrae RR, Costa Jr PT. A contemplated revision of the NEO Five-Factor Inventory. Pers Individ Dif 2004; 36(3):587-96.

21. Garousi Farshi MT, Mehryar AH, Ghazi Tabatabaei SM. Application of the new NEO I-R test and analytic evaluation of it"s characteristics and factorial structure among iranian university students. Journal of Humanities 2001; 11(39):173-98.

22. Mirzae G, Mehrabi H, Ghahvehchi-Hosseini F, FathiAshtiani A. Psychometric properties of the personality characteristics questionnaire among militaries. Journal of Military Medicine 2015; 17(1):17-23.

23. Maslach Ch, Jackson SE, Leiter MP. Maslach burnout inventory manual. 3rd ed. Palo Alto, California, United States: Consulting Psychologists Press; 1996.

24. Filian A. The study of burnout and its relationship with coping mechanisms nurses Tehran. [Msc thesis]. Tehran: Tarbiat Modares University; 1992.

25. Uchaikin VV, Zolotarev VM. Chance and Stability, stable distributions and their applications. $1^{\text {st }} \mathrm{ed}$. Ulyanovsk, Russian Federation: Ulyanovsk State University; 1999.

26. Kwak SG, Kim JH. Central limit theorem: the cornerstone of modern statistics. Korean J Anesthesiol 2017; 70(2):144-56.

27. Wurm W, Vogel K, Holl A, Ebner C, Bayer D, Mörkl S, et al. Depression-burnout overlap in physicians. PLoS One 2016; 11(3):e0149913.

28. Kalani SD, Azadfallah P, Oreyzi HR, Azizkhani R, Adibi P. Prevalence of burnout syndrome among the residents in Isfahan University of Medical Sciences, Isfahan, Iran. Journal of Isfahan Medical School 2017; 35(442):993-9.

29. Mahdizadeh M, Vafaei A, Taghipour A, Esmaeily $H$, Mahdizadeh SM. Occupational burnout and influence of work environment factors among family physicians in Khorasan Razavi. Occupationl Medicine Quartely Journal 2014; 5(4):42-51.

30. Atef L, Rooh-al-amin M, Noori A, Molavi H. A comparision of job burnout in general surgeons and internists in Isfahan. Knowledge \& Research in Applied Psychology 2006; 8(29):129-51.

31. Moharamzadeh M, Vahdani M, Ghahremani J, Sayed Ameri MH. The relationship between employees' personality characteristics and job burnout in ministry of sport and youth. Journal of Sport Management 2015; 6(4):697-711.

32. Esfahani MS, Mirzaee M, Boroumandfar K, Abedi MR. Job burnout and its relation with personality traits among the midwives working in Isfahan, Iran. Iran J Nurs Midwifery Res 2012; 17(3):220-4.

33. Magnano P, Paolillo A, Barrano C. Relationships between personality and burn-out: an empirical study 
with helping professions' workers. International Journal of Humanities and Social Science Research 2015; 1:10-9.

34. Ahmadi MS. Predicting job stress and burnout based on personality characteristics of nurses. Knowledge \& Research in Applied Psychology 2016; 17(2):98-107.

35. Soltaniyan MA, Aminbeidokhti AA. The role of sport on job burnout of employees. koomesh 2009; 10(4):2816.

36. Sharma A, Kashyap N. The influence of the big five personality traits on burnout in medical doctors. Int $\mathrm{J}$ Psychol Stud 2017; 9(4):13-23.

37. Swider BW, Zimmerman RD. Born to burnout: a metaanalytic path model of personality, job burnout, and work outcomes. J Vocat Behav 2010; 76(3):487-506.

38. Azeem SM. Personality hardiness, job involvement and job burnout among teachers. International Journal of Vocational and Technical Education 2010; 2(3):3640.

39. Jalali Farahani M, Sajjadi SN, Ali Doost Ghahfarokhi E, Eslami Y. The relationship between personality dimensions and job burnout in physical education men teachers of Zanjan. Contemporary Studies on Sport Management 2012; 1(1):37-48.

40. Bagheri $\mathrm{Gh}$, Zareimatin $\mathrm{H}$. The relationship between leadership style of football coaches with the degree of players' burnout and the presentation of the model. Organizational Culture Manegement 2005; 3(3):3565.
41. Ghorpade J, Lackritz J, Singh G. Burnout and personality: evidence from academia. Journal of Career Assessment 2007; 15(2):240-56.

42. Vahdani M, Moharram Zadeh M, Seyyed Ameri MH. The correlation between personality dimensions (FiveFactor Model) and job burnout in teachers of exceptional schools in North Khorasan. Journal of Exceptional Education 2013; 5(113):5-14.

43. Fernández-Castro J, Martínez-Zaragoza F, Rovira T, Edo S, Solanes-Puchol Á, Martín-del-Río B, et al. How does emotional exhaustion influence work stress? relationships between stressor appraisals, hedonic tone, and fatigue in nurses' daily tasks: a longitudinal cohort study. Int J Nurs Stud 2017; 75:43-50.

44. Guan S, Xiaerfuding X, Ning L, Lian Y, Jiang Y, Liu J, et al. Effect of job strain on job burnout, mental fatigue and chronic diseases among civil servants in the xinjiang uygur autonomous region of China. Int $\mathrm{J}$ Environ Res Public Health 2017; 14(8):E872.

45. Ehyakonandeh $M$, Shafiabadi $A$, Sodani $M$. Effectiveness of dawis career counseling of work adjustment method in decrease of the emotional exhaustion of Islamic Azad Univercity Behbahan female employees. Journal of Career and Organization Counseling 2010; 2(4):29-45.

46. Bhagat V, Haque M, Simbak NB, Jaalam K. Study on personality dimension negative emotionality affecting academic achievement among Malaysian medical students studying in Malaysia and overseas. Adv Med Educ Pract 2016; 7:341-6. 